\title{
Approaches to teaching: current opinions and related research
}

Published by Elsevier

\section{Maggi Banning, B.Sc. (Hons), M.Sc. PGDE, EdD, SRN, SCM.}

\section{Approaches to Teaching}

The changing face of teaching has moved away from didacticism to learning facilitation and with this is the need for teachers to play different roles and use new techniques (Griffin, 2002, Jarvis, 2002). Three main styles of teaching are propounded; didactic, socratic and facilitative. The diversity of styles provides a degree of flexibility that allows one to alter the task of teaching whether it is teacher-centred or student-centred. Jarvis (2002) views teaching as both an art and a science. In doing so, one can combine the authoritarian didacticism approach with the democratic facilitator's approach with no limit on the combinations.

The lecture is "probably the most frequently employed teaching technique despite all the criticisms that have been levelled against it" (Jarvis, 1983 p 117). It is "an economical means of transmitting factual information to a large audience, although there is no guarantee that effective learning will result" (Walkin, 2000, p 55). The didactic approach to teaching primarily involves lecturing and is essentially teacher-centred (Entwistle, 1997). Fry, Ketteridge \& Marshall (2003) reminds us that although the lecture remains a major method of teaching in adult and continuing education, and is still recognised "as a 
useful teaching tool" as it can provide a framework of ideas and theories but it needs to be complemented by interaction and adult-oriented strategies due to attention span and lack of participation.

Didacticism raises numerous constraints which involve rote learning, learning by note taking, and potential boredom as the approach limits student participation and reflection. Many traditional lecturers continue to use the lecture as a means of teaching, especially when the subject is new to the majority of students or if the students are teacher dependent, anxious or disorganised as learners (Walkin, 2000).

Radical pedagogies have challenged conventional classroom practice where the student is the recipient of new knowledge and the teacher is the knower. Teaching is "no longer seen as imparting knowledge and doing things to the student, but is redefined as facilitation of self-directed learning" (Tight, 1996, p 26). In an attempt to alter this position, the teacher can use problem-solving techniques and vicarious learning strategies to encourage students to articulate and theorize what they know already in relation to the meaning of their experiences and their interpretation (Preece \& Griffin, 2002). Sharing of experiences allows students to critically think and undertake structured reflection on how the events may influence their personal circumstances. This facilitative approach to teaching teases out previous learning and helps students 'make sense' of experiences in relation to real world events (Gregory, 2002). Experiential learning reflects the ontology of the learner and can impact on both propositional and process knowledge forms 
(Knowles et al., 1998) and in doing so, make a positive contribution to the students' learning, motivation and their ability to become self-directive.

In order to facilitate learning, teachers must be competent, possess self-esteem, hold authority within the classroom, show compassion, respect for individuals and be flexible in the range and style of teaching methods. They can be challenged and should be able to form relationships between themselves and the students (Freeth \& Parker, 2003). To be effective facilitators, teachers need to be accomplished in the educational attributes they may want students to acquire.

The "qualities that exist in the personal relationship between the facilitator and the learner" are important (Rogers, 1989, p 121). This emphasis on the facilitation of learning correlates with the humanistic approach to learning and represents a shift from didactic exposition to one of empowering the student to learn theory and skills. The facilitator's role is one that encourages students to engage in intellectual analysis, critically think, problem solve, describe experiences (Haith-Cooper, 2003, Gregory, 2002) and challenge learning (Haith-Cooper, 2000). Challenge is an aspect of learning facilitation that is commensurate with transformational learning (Entwistle, 1997).

Different styles of facilitation are established (Gilmartin, 2001). Didactic-experiential is viewed as the least effective facilitative method, as lecturers can become defensive whilst engaging in group work and fail to address high-level challenges from students (Gilmartin, 2001). Poor facilitation of learning can have a detrimental effect on student 
morale, and induce reduced confidence and motivation to achieve (Banning, 2004). Lecturers who fall into this category are essentially ill-equipped to undertake learning facilitation, as they may not appreciate the professional constraints that influence the learning environment (Haith-Cooper, $2000 \& 2003$ ). In contrast critical pedagogy is the most facilitative style of facilitation, as it hands over the responsibility for learning to the student as they debate cognitive and intuitive perceptions (Gilmartin, 2001). These features are commensurate with the development of academic awareness and clinical reasoning skills in students and concur with the characteristics of student empowerment (Brookfield, 1996).

Although the facilitation of learning caters for the adult learner (Knowles, 1990), to succeed in this approach, students require the theoretical ingredients for effective and comprehensive learning and the acquisition of skills in clinical reasoning. To achieve this students require a compilation of learning materials and academic support; both elements are crucial, especially when the discipline is unfamiliar. Failure to provide these elements will result in surface learning which is based on the memorization of poorly comprehended theory (Marton \& Säljö, 1997, Banning, 2004).

The socratic method of teaching also emphasises student-centredness and strongly opposes didacticism. Brownhill (2002) illustrates how teachers can use either authoritarian or non-authoritarian socratic teaching positions to enhance students to learn independently and become critical thinkers. Teachers provide the initial theoretical positions and introduce the associated inconsistencies and attributes in an attempt to raise 
awareness in students, initiate reflection and ponder on the key concepts. Both autocratic and non-autocratic teaching approaches equally enhance the ability of students to conceptualise and reflect on positions.

\section{Teaching scientific disciplines}

For more than a decade, the difficulty of teaching scientific theory to nurses has been debated. Key concerns focus on the variance in student comprehension, the disproportionate allocation of scientific and non-scientific subjects within curricula and the continual use of ineffective teaching strategies (McKee, 2002, Davies et al., 2000). The theory practice divide appears wider due to inappropriate clinical application (Tanner, 2000). This deficit contributes to the inadequate scientific preparation of nurses and a workforce that are unable to articulate the relevance of biological knowledge to clinical situations, or communicate scientific information to patients and their relatives (Clancy et al., 2000, Latter et al., 2000). Theoretical deficits in pharmacology are also apparent and require theoretical models to encourage improved teaching by nurse educators (Banning, 2003). My study explored the participants' experience of teaching on an independent nurse prescribing course, findings indicated that knowledge transmission was the predominant teaching strategy used with little emphasis on the application of theory to practice. Self-directed study strategies were used as a back-up strategy even though students were provided with negligible academic support and guidance. In this situation, academic engagement of students was limited. Lecturers on this course needed to incorporate process oriented teaching strategies such as problem solving, case analysis, 
think aloud seminar and simulation to facilitate students learning of the scientific elements of prescribing (Banning, 2004).

\section{Teaching practical skills}

For learners undertaking vocational training, the skills to be taught should "resemble the real task, even if some of the distractions and complications of the real world have to be stripped away to lay bare the skeleton of the skill” (Rogers, 1989, p 49). When the skills to perform a specific job are based on a selective foundation, these skills are referred to as competencies and "the qualification will be based on competencies" (Rogers, 1989, p 50). In order for a learner to acknowledge and understand a specific skill it must be dissected into sub-components so that the learner can visualise the importance and relevance of each component. Students must be able to practice each sub-component of the skill and visualise its relevance. Practice allows the learner to reinforce the skill (Laurillard, 1997).

\section{Addressing students' needs}

In every classroom, one may find people of mixed ability; how can the teacher meet the learning needs of all students? Rogers (1989) relates the need to break away from onepace teaching to use flexibly-paced, multi-resourced learning strategies, also by setting clear objectives and ensuring that everyone meets these using a set standard to indicate achievement. Initially, the teacher needs to explore who the students are in the group, set 
out the housekeeping rules for the class group and objectives for teaching on the course. It is important to relax the students and allow students to set their own learning objectives and later involve them in project work to support their learning (Gosling, 2003).

Brookfield, (1996) provides a summary of the components of students' learning needs and explores how to implement an environment conducive to learning. He suggests that students' learning needs can be met when teaching is facilitative rather than didactic and when the teacher acknowledges the learning needs, past experiences, relevant application and individual styles of learning of students when designing learning activities. Findings from my study on the student experience of studying to become independent nurse prescribers support these considerations (Banning, 2004). Students' conceptions of adult learning involved the need to comprehend the relevance of theory in order to apply and assimilate it and also to be offered opportunities to share vicarious experiences with peers. The exploration of students' views revealed the need for constructivist teaching methods (Hendry et al., 1999), rather than knowledge transmission to teach the applied pharmacology component of the course (Banning, 2004).

\section{Assessing learning within classroom situations}

Laurilliard (2002) reminds us that students attend courses with their individual presage variables. These variables provide some insight on the subtle differences that illustrate the uniqueness of each adult learner. These variables include; motivation, expectations, knowledge retention in relation to short and long term memory, knowledge, skills, 
competencies and experience, powers of concentration, problem solving ability, access to student support facilities, study time available, learning capacity and orientation to learning (Walkin, 2000). These variables influence the capacity for students to learn. The teacher needs to assess learning achievement in order to proceed with the curricular content but also to ensure students are maintaining the pace of learning. In my study, I found that the mature learners experienced difficulties maintaining the pace of learning when the rate of learning was much slower. This inability to maintain the pace of learning caused extreme anxiety, distress and unhappiness amongst students (Banning, 2004). This feature agrees with previous studies and is not uncommon in professionals who have employment and domestic responsibilities (Jarvis, 1983).

Perhaps the most common method of assessing student learning involves objective questioning during teaching. Effective teaching strategies that encourage answers to simple, uncomplicated questions followed through by more complex questions or tasks enables the teacher to explore the depth of comprehension of students. In situations where students have been preconditioned not to question by indoctrination into apprenticeship style teaching, diffident students can be encouraged to communicate with peers and lecturers using quizzes, formative assignments, think-aloud seminars, self-assessment work, group work, problem solving scenarios, case analysis, role play, simulations, film critiques, speed reading and research appraisal (Lee \& Ryan-Wenger, 1997). These teaching and learning methods can encourage creative discussion and provide opportunities for teachers to offer meta-cognitive questions to stimulate students to think critically make associations between theory and practice, openly debate and think 
laterally using their personal and learning experience and new knowledge to develop understanding (Gregory, 2002).

\section{Promoting graduateness in students}

Graduates may be differentiated by their ability to critically think, use problem solving strategies to solve enigmas and incorporate evidence and research mindedness to justify decisions and solutions. The concept of graduateness refers to the development and utilisation of both intellectual and transferable skills that encompass structured reflection, critical thinking, analytical skills, leadership, research awareness, creative thought and reasoning strategies. Critical thinking is conceptualised as an intellectual ability which involves a reflective dimension. It is also a process which can be fostered by creative thought, challenging the accuracy and validity of assumptions, beliefs and the context of problem, the capacity to imagine and explore alternatives, and formulate alternatives (Brookfield, 1987). Learners who portray critical thinking ability may challenge trigger events, appraise or explore a situation following a trigger event then develop alternative perspectives and integrate the event.

Although critical thinking is an important skill that encourages individuals to be objectively analytical and reflective, both elements are essential for professional effectiveness (Argyris \& Schön, 1995) but arguably not all learners have the capability to become critical thinkers. So, teachers need to motivate and engage students in learning to assist this form of development. Many students attribute their poor performance to 
personal characteristics and therefore fail to sufficiently engage in deep learning, often due to devaluation of the benefits of education (Hufton et al., 2002).

\section{Preparing students for new roles and responsibilities}

To prepare learners for new roles and responsibilities they need to acquire both professional and university education to develop professional performance. To become an experienced clinician who is proficient in clinical reasoning, a nurse has to attain specific clinical practice and develop nursing judgment, supported by a graduate academic background (O'Neill \& Dluhy, 1997). This combination can provide a foundation for cognitive and psychomotor skill development that is essential for proficient clinical reasoning (Cooke \& Moya, 2002).

Although clinical reasoning is the hallmark of the nursing expert (Davies \& Hughes, 1995), the debate on the sub-components of it continues (Flower, 1997). Proposed subcomponents include reflection, critical thinking, diagnostic reasoning, nursing experience and nursing judgment. Reflection can be construed as a cognitive processing aspect of critical thinking (O’Neill \& Dluhy, 1997); thus, it is an important skill. Reflection can be achieved by structured processing of experiences and teacher-centred problem-solving exercises (Seymour et al., 2003, Liimatainen et al., 2001). Students can reiterate "significant experiences of learning to others which is itself a reflective way for both the teller and the audience to learn more about the experience by interactively weaving together theory and practice with humane threads" (Cortazzi et al., 2001, p257). 
The students' learning of new roles needs to be assessed both theoretically and clinically. The value of the assessment can only be as a credible as the individual assessor (While, 1994). Clinical assessors need to be familiar with assessment strategies, professional roles and guidance and instruction on the assessment and mentoring of students (Myrick \& Yonge, 2001). Networking strategies can also be a useful support (Watkins, 2000, Duffy \& Watson, 2001).

The inclusion of multiple forms of assessments would help students integrate, synthesize and assimilate the theoretical components of the new roles with the clinical application and practical skills involved. This approach is valuable as it would not only incorporate strategies to promote critical thinking but would also be a powerful tool to assess the overall performance and ability of students to clinically reason and can serve as a safety net if performance is below average in any assessment. Opportunities should be available for students who fail an assignment to demonstrate that with increasing nursing experience and consolidation of theory with practice, academic and clinical performance can improve. Moreover, this approach can encourage the student to problem-solve, undertake team work, learn from peers, enhance the integration, synthesis and conceptualization of knowledge (Cooke \& Moya, 2002).

An important aspect of professional competency is feedback on clinical performance and this is a requisite indicator for learner development and confidence building. Ideally, students should be provided with feedback on clinical performance. The feedback 
sandwich is a useful approach to communicate performance (Glover, 2000). Clinical assessors should be encouraged to utilize this method with students.

The experience of learning and achievements encountered can be reflected on and a narrative account provided (Gallacher, 2001). The narrative can then be used to assess the students' clinical reasoning skills in particular their cognitive skills, critical thinking or situation-bound thinking and personal reflection (Fowler, 1997).

\section{Conclusion}

Three approaches to established, each has its own merits and usefulness in adult learning. The use of didactic and self directed approaches to teaching should be limited and approaches that are student-centred such as process oriented approaches to teaching should be encouraged particularly in teaching scientific topics, questioning and preparing nurses for prescribing roles. Learning facilitation should be encouraged with effective preparation strategies in place to train lecturers to effectively use these methods.

\section{References}

Banning, M, (2003). Pharmacology Education: A theoretical framework of applied pharmacology and therapeutics. Nurse Education Today,23: 459-466.

Banning, M. (2004). An illuminative evaluation of the teaching and learning experience of participants' teaching and studying on an independent nurse prescribing course. Unpublished EdD thesis. 
Brookfield, S.D. (1987).Developing Critical Thinkers. Challenging Adults to Explore Alternative Ways of Thinking and Acting. California Open University Press, pp. 1-51.

Brookfield, S.D. (1996). Understanding and Facilitating Adult Learning. Milton Keynes: Open University Press. pp.1-49.

Brownhill, B. (2002). The Socractic Method. In P.Jarvis (Ed). The Theory and Practice of Teaching. London:Kogan Page. pp.70-78.

Clancy, J., McVicar, A. \& Bird. D. (2000). Getting it right ?. An exploration of issues relating to the biological sciences in nurse education and nursing practice. Journal of Advanced Nursing, 32: 1522-1532.

Cooke, M. \& Moya, K. (2002). Students' evaluation of problem-based learning. Nurse Education Today, 22: 330-339.

Cortazzi, M., Jin, L., Wall, D. \& Cavendish, S. (2001). Sharing learning through narrative communication. International Journal of Communication Disorders, 36, supplement 2001: 252-257.

Davies, S., Murphy, F. \& Jordan, S. (2000). Bioscience in the pre-registration curriculum: finding the right teaching strategy. Nurse Education Today, 20: 123-135.

Entwistle, N. (1997). Contrasting Perspectives on Learning. In The Experience of Learning. Implications for Teaching and Studying in Higher Education. Marton, F., Hounsell, D. \& Entwistle, W.J. (ed). $2^{\text {nd }}$ Edition. Edinburgh: Scottish Academic Press. pp 3-22.

Freeth, D. \& Parker, P. (2003). Key aspects of teaching and learning in nursing and midwifery. In H., Fry, S. Ketteridge, S. \& S. Marshall. (Eds) A Handbook of Teaching \& Learning in Higher Education. Enhancing Academic Practice. $2^{\text {nd }}$ Edition, London: Kogan Page. pp. 324-343.

Fry, H., Ketteridge, S. \& Marshall, S. (2003) (Eds). A Handbook for Teaching \& Learning in Higher Education. Enhancing Academic Practice. $2^{\text {nd }}$ Edition, London: Kogan Page. pp. 9-26. Gregory, J. (2002). Facilitation and facilitator style. In P.Jarvis (Ed). The Theory and Practice of Teaching. London: Kogan Page, pp 79-93

Hendry. G.D., Frommer, M. \& Walker, R.A. (1999). Constructivism and problem-based learning. Journal of Further and Higher Education, 23, 359-371. 
Nurse Education Today, Volume 25, Issue 7, Pages 502-508 